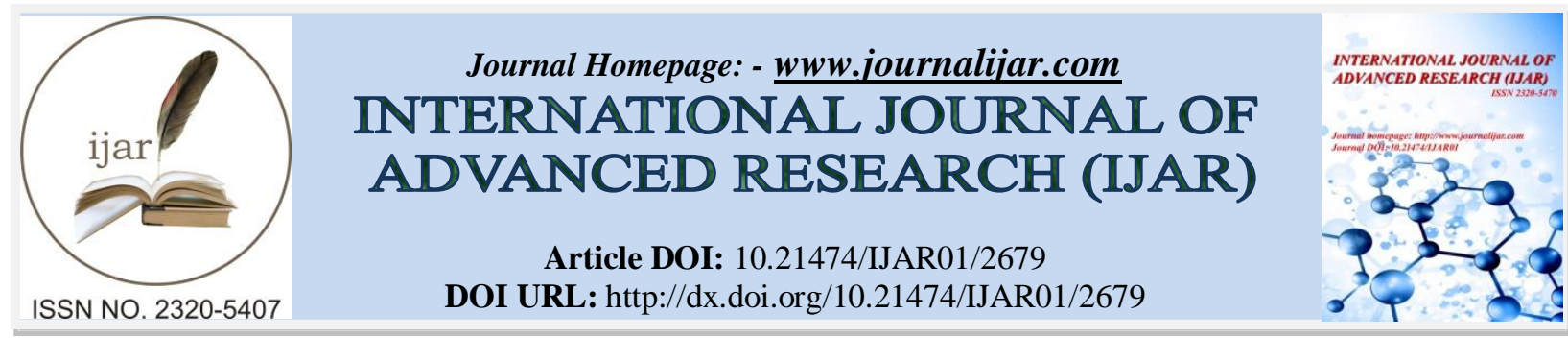

RESEARCH ARTICLE

\title{
THE EFFECT OF IRON AND ERYTHROPOIETIN TREATMENT ON THE HBA1C OF HEMODIALYSIS PATIENTS WITH DIABETES.
}

Ayman M. El-Badawy, Mohamed YehiaSeddek and Mohamed Shawky El-sayed Samira Marawan Hassan. Internal medicine department,Faculty of medicine, Banha University ,Qalyubia, Egypt.

\section{Manuscript Info}

Manuscript History

Received: 31 October 2016

Final Accepted: 01 December 2016

Published: December 2016

\section{Abstract}

Background \& Aims:- The aim of this thesis is to validate the effect of iron and erythropoietin treatment on theHbAlc of hemodialysis patients with diabetes.

Methods:- This study was conducted on 50 HD patients with type-2 diabetes.All patients were selected from those under going regular HD in nephrology and dialysis unit inBanha University Hospitals.

.the diagnosis of diabetes will be based on a history of diabetes or on the ADA criteria. The patients will be classified into two groups (each consists of 25 patients). The first group (group A) are patients selected for iron therapy according to clinical need.The second group (group B) consisted of patients who were those needing ESA treatment.Glycemic control in both patient groups will be assessed using $\mathrm{HbAlc}$ in the month leading up to treatment and once again for a 4-week period 4 months after therapy. The main values of the threemonthly measurements of casual.

Results:- A1C value falls after four months of therapy in both groups(iron and ESA group) compared to before therapy this change was independent on glycemic control.

Conclusions:- A1c is the most widely accepted and used method of assessing chronic glycemia in patients with diabetes. This is study showed that iron and ESA treatments result in a fall in A1C, which is independent of glycemic changes in patients with diabetes and CKD.

Copy Right, IJAR, 2016,. All rights reserved.

\section{Introduction:-}

A1c is the most widely accepted and used method of assessing chronic glycemia in patients with diabetes. It is formed by the irreversible binding of glucose to hemoglobin over the lifespan of the erythrocytes (Goldstien et al, 2004).Patients with Chronic kidney disease (CKD) are commonly anemic due to a variety of reasons, including functional or absolute iron deficiency and erythropoietin insufficiency. Treatment of anemia in patients with CKD using iron replacement therapy and erythropoietin-stimulating agents (ESAs) has resulted in significant improvements to quality of life and the correction of anemia without the need for blood transfusions(Nissenson et al, 1999).

Corresponding Author:- Ayman M. El-Badawy. 


\section{Material and Methods:-}

This study was conducted on $50 \mathrm{HD}$ patients with type-2 diabetes.All patients were selected from those undergoing regular HD in nephrology and dialysis unit inBanha University Hospitals. The diagnosis of diabetes was based on a history of diabetes or on the ADA criteria. Information collected from participants included demographic data, height, weight (dry weight in HD patients), duration of diabetes and duration of HD.

Inclusion criteria:- Patients with type $2 \mathrm{DM}$ who fulfil the following criteria; regular $\mathrm{HD}$, anemia due to CKD, Patients with diabetes were restricted to those with stable blood glucose and whose diabetes treatment had not been altered during the preceding 6 months before the determination of $\mathrm{HbA} 1 \mathrm{c}$.

Exclusion criteria:- Patients with hemoglobinopathy, anemia due to causes other than CKD, patients who had a history of overt blood loss or who received a blood transfusion 4 months prior to the study, patients with evidence of scurvy, evidence of hepatic disorders, inflammatory disease or thyroid disease, who had been previously treated with ESA on renal replacements, or with previous transplantation were excluded from the study.The patients will be classified into two groups (each consists of 25 patients).The first group (group A): serum ferritin values $<200 \mu \mathrm{g} / \mathrm{l}$ ) these patients were candide for iron therapy. The second group (group B): serum ferritin value $>200 \mu \mathrm{g} / \mathrm{l}$ these patients were candide for ESA therapy.Glycemic control in both patient groups was assessed using HbA1c in the month leading up to treatment and once again for a 4 -week period 4 months after therapy.Blood was drawn without overnight fasting, immediately before the session of HD.Blood was drawn from the dialyzer circuit prior to the initiation of dialysis or administration of anticoagulants. Blood samples were divided into $5 \mathrm{ml}$ sent for HbA1c and 5 $\mathrm{ml}$ centrifuged with the serum frozen at $80 \mathbf{C}^{\circ}$ for measurement of GA, $8 \mathrm{ml}$ will be analyzed for total protein, albumin, blood urea nitrogen and creatinine and $2 \mathrm{ml}$ on EDTA for CBC.All the patients selected for iron therapy had either absolute or functional iron deficiency as evidenced by serum ferritin values $<200 \mu \mathrm{g} / \mathrm{l}$. All patients had hemoglobin $\leq 10.5 \mathrm{~g} / \mathrm{dl}$. Patients in this group were not on previous or concurrent ESA therapy and were vitamin B12 and folate replete. Intravenous iron was given as a single dose in the form of low-molecular weight iron dextran dependent on the patient's body weight. This will delivered as an initial intravenous test infusion of $100 \mathrm{mg}$ of iron over $1 \mathrm{~h}$ followed by the remaining dose over the next 2-4 h.All patients receiving ESA therapy had hemoglobin < or $=10.5 \mathrm{~g} / \mathrm{dl}$ and were considered iron, vitamin B12, and folate replete prior to initiation. Patients were considered iron replete following a serum ferritin value $>200 \mu \mathrm{g} / \mathrm{l}$ or having received intravenous iron at least 6 weeks prior to ESA therapy.The dose of ESA will be titrated monthly to achieve target hemoglobin 10.5-12 $\mathrm{g} / \mathrm{dl}$.

\section{Statistical analysis:-}

The collected data were tabulated and analyzed using SPSS version 16 soft ware (SpssInc, Chicago, ILL Company) and. Categorical data were presented as number and percentages while quantitative data were expressed as mean \pm standard deviation, and range. Categorical variables were analyzed using Chi square test (X2) and Fisher's exact test (FET). Quantitative data were tested for normality using Shapiro- Wilks test, assuming normality at P>0.05. St."t test was used to analyze the difference between 2 independent groups regarding normal variables, non parametric variables were analyzed using Man Whitney $\mathrm{U}$ test (MWU) for 2 independent groups and Friedman test which was used to test the differences between matched variables considering $P$ value significant at 0.05 . Significant Friedman test was followed by post hoc multiple comparisons using Bonferroni adjusted Wilcoxon test to detect the significant pairs at adjusted $\mathrm{P}=0.017$

\section{Results:-}

Table 1:- Socio-demographic characters of the studied groups.

\begin{tabular}{|l|l|l|l|}
\hline Variable & No. $(\mathrm{n}=50)$ & $\%(100.0)$ \\
\hline Group & $\begin{array}{l}\text { Group A } \\
\begin{array}{l}\text { S. ferretin<200, iron } \\
\text { therapy) }\end{array}\end{array}$ & 25 & 50.0 \\
\cline { 2 - 4 } & $\begin{array}{l}\text { Group B } \\
\text { S. ferretin>200, ESA } \\
\text { therapy) }\end{array}$ & 25 & 50.0 \\
\hline \multirow{2}{*}{ Sex } & Male & 22 & 44.0 \\
\hline & Female & 28 & 56.0 \\
\hline Age (ys) & Mean \pm SD & Range \\
\hline
\end{tabular}




\begin{tabular}{|l|l|l|}
\hline Weight $(\mathrm{kg})$ & $79.8 \pm 17.8$ & $56-110$ \\
\hline Height $(\mathrm{cm})$ & $162.2 \pm 8.05$ & $150-175$ \\
\hline BMI $\left(\mathrm{kg} / \mathrm{m}^{2}\right)$ & $30.07 \pm 5.1$ & $23.2-40.2$ \\
\hline
\end{tabular}

50 studied patient group (A):25 patients and Group(B):25 patients Among 50 studied patient 22patients were male, 28 patients were female Mean age(ys):56.3 of range from 40 to 65 years Mean weight( $\mathrm{kg}$ ): 79.8 of range from 56 to $110 \mathrm{~kg}$ Mean height $(\mathrm{cm}): 162.2$ of range from150 to $175 \mathrm{~cm}$ Mean pmi $(\mathrm{kg} / \mathrm{m}): 30.07$ of range from 23.2 to 40.2 $\mathrm{kg} / \mathrm{m}$

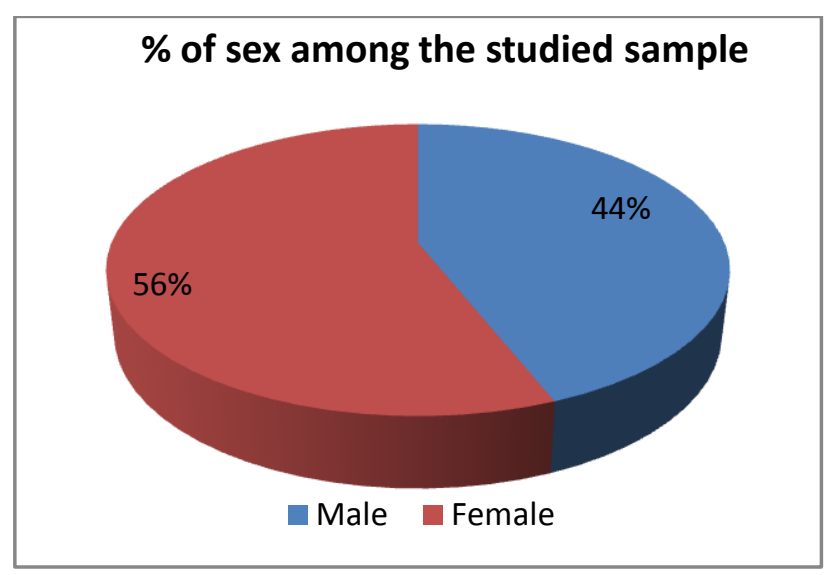

Fig. 1:- $\%$ of sex among the studied groups.

Table 2:- Comparison of the studied groups regarding socio-demographic characters.

\begin{tabular}{|c|c|c|c|c|c|c|c|}
\hline \multicolumn{2}{|l|}{ Variable } & \multicolumn{2}{|c|}{$\begin{array}{c}\text { Group A } \\
(\mathrm{N}=25)\end{array}$} & \multicolumn{2}{|c|}{$\begin{array}{l}\text { Group B } \\
(\mathrm{N}=25)\end{array}$} & \multirow{2}{*}{$\begin{array}{l}\text { Test of } \\
\text { significanc } \\
\text { e }\end{array}$} & \multirow[t]{2}{*}{$\mathrm{P}$} \\
\hline & & No. & $\%$ & No. & $\%$ & & \\
\hline \multirow[t]{2}{*}{ Sex } & Male & 8 & 32.0 & 14 & 56.0 & $\mathrm{X}^{2}=$ & 0.09 \\
\hline & Female & 17 & 68.0 & 11 & 44.0 & 2.92 & (NS) \\
\hline Age (ys) & $\begin{array}{l}\text { Mean } \pm \text { SD } \\
(\text { Range) }\end{array}$ & \multicolumn{2}{|c|}{$57.1 \pm 3.2(52-60)$} & \multicolumn{2}{|c|}{$55.6 \pm 7.4(40-65)$} & $\begin{array}{l}\text { St."t"= } \\
0.95\end{array}$ & $\begin{array}{l}0.34 \\
(\mathrm{NS}) \\
\end{array}$ \\
\hline Weight (kg) & $\begin{array}{l}\text { Mean } \pm \text { SD } \\
\text { (Range) }\end{array}$ & \multicolumn{2}{|c|}{$\begin{array}{c}75.4 \pm 17.4 \\
(56-103)\end{array}$} & \multicolumn{2}{|c|}{$\begin{array}{l}84.0 \pm 17.5 \\
(60-110)\end{array}$} & $\begin{array}{l}\text { St."t"= } \\
1.74\end{array}$ & $\begin{array}{l}0.09 \\
(\mathrm{NS})\end{array}$ \\
\hline Height $(\mathrm{cm})$ & $\begin{array}{l}\text { Mean } \pm \text { SD } \\
\text { (Range) }\end{array}$ & \multicolumn{2}{|c|}{$\begin{array}{l}159.8 \pm 6.2 \\
(152-170)\end{array}$} & \multicolumn{2}{|c|}{$\begin{array}{l}161.2 \pm 9.6 \\
(150-175)\end{array}$} & $\begin{array}{l}\text { St."t"= } \\
0.59\end{array}$ & $\begin{array}{l}0.55 \\
(\mathrm{NS})\end{array}$ \\
\hline BMI $\left(\mathrm{kg} / \mathrm{m}^{2}\right)$ & $\begin{array}{l}\text { Mean } \pm \text { SD } \\
(\text { Range) }\end{array}$ & \multicolumn{2}{|c|}{$\begin{array}{l}29.4 \pm 5.9 \\
(23.2-40.2)\end{array}$} & \multicolumn{2}{|c|}{$\begin{array}{l}30.7 \pm 5.1 \\
(25.0-36.75\end{array}$} & $\begin{array}{l}\text { St."t"= } \\
0.96\end{array}$ & $\begin{array}{l}0.34 \\
(\mathrm{NS})\end{array}$ \\
\hline
\end{tabular}

Among studied groups Group A formed from 8 male and 17 female patientsGroup B formed from 14 male and 11 female patients in group A mean age 57.1 and in groupB mean age 55.6which statistically non significant ( $p=.34$ ) in group A mean weight was 75.4 and in groupB mean weight was 84 which statistically non significant ( $\mathrm{p}=.09$ )in group A mean height was 159.8 and in groupB mean height was 161.2 which statistically non significant ( $\mathrm{p}=.55)$ in group A mean BMI was 29.4 and in groupB mean BMI was 30.7 which statistically non significant $\quad(p=.34)$ 
Table 3:- Comparison of the studied groups regarding duration of DM and hemodialysis.

\begin{tabular}{|l|l|l|l|l|l|l|l|l|}
\hline \multirow{2}{*}{ Variable } & \multicolumn{3}{l|}{ Group A (N=25) } & \multicolumn{2}{l|}{ Group B (N=25) } & \multirow{2}{*}{ St. 't' } & \multirow{2}{*}{ P } \\
\cline { 2 - 9 } & Mean & \pm SD & Range & Mean & \pm SD & Range & & \\
\hline Duration of DM (ys) & 14.52 & 5.12 & $10-25$ & 12.92 & 5.75 & $4-25$ & 1.04 & $0.3(\mathrm{NS})$ \\
\hline Duration of HD (ys) & 3.48 & 2.44 & $1-8$ & 2.84 & 1.69 & $1-6$ & 1.08 & $0.28(\mathrm{NS})$ \\
\hline
\end{tabular}

\section{Among studied groups:-}

In group A mean duration of DM was 14.52 and in group B mean duration of DM was 12.92 which statistically non significant $(\mathrm{p}=.3)$

In group A mean duration of HD was 3.48 and in group B mean duration of HD was 2.84 which statistically non significant $(\mathrm{p}=.28)$

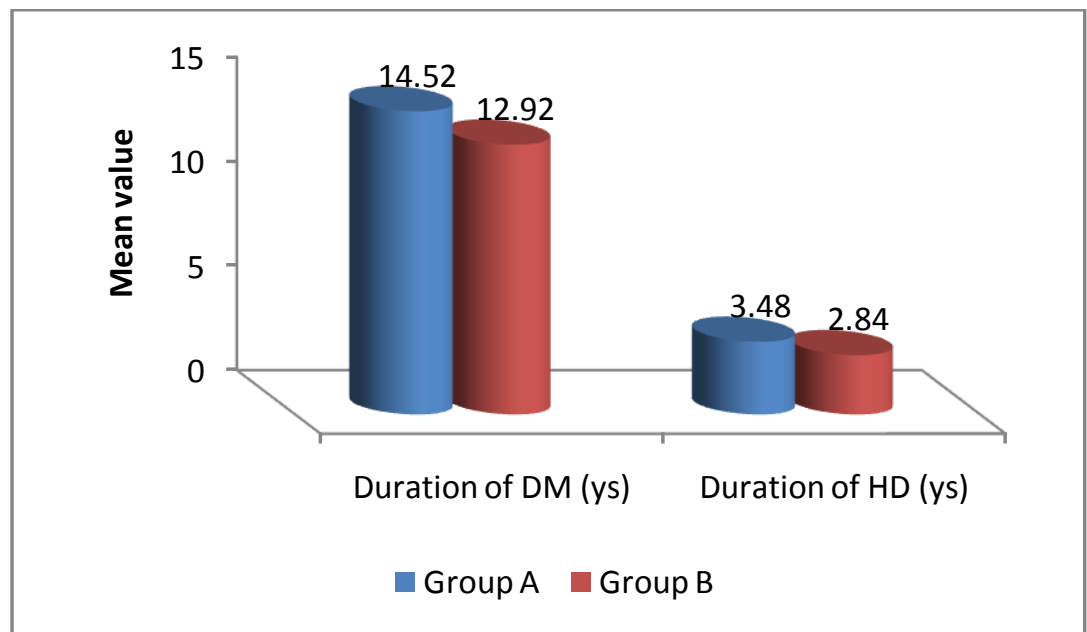

Fig. 2:- Duration of DM and HD among groups

Table 4:- Comparison of the studied groups regarding type of treatment.

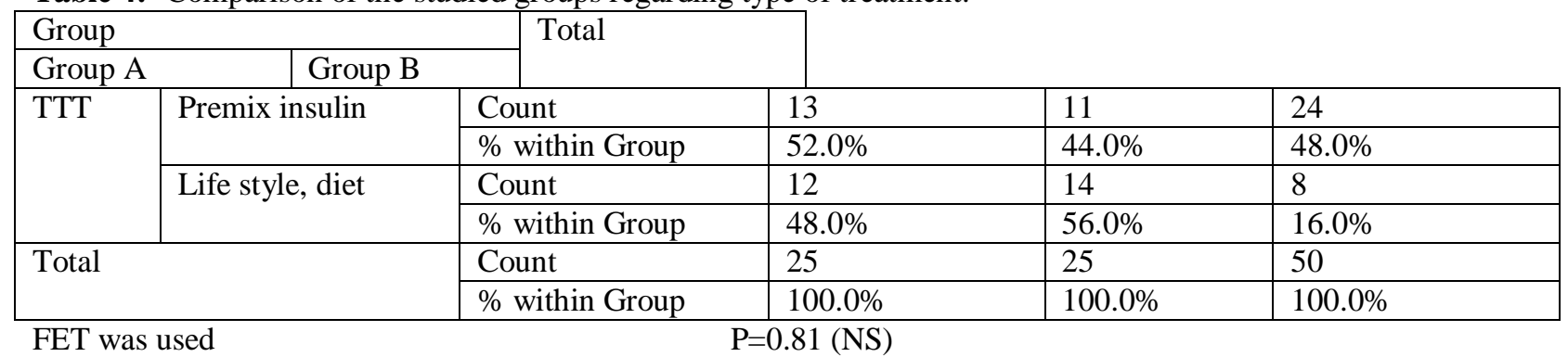

This table show regimen for glycemic control for both groups.

Table 5:- Comparison of the studied groups regarding laboratory findings before treatment.

\begin{tabular}{|c|c|c|c|c|c|c|c|c|}
\hline \multirow[t]{2}{*}{ Variable } & \multicolumn{3}{|c|}{ Group A $(\mathrm{N}=25)$} & \multicolumn{3}{|c|}{ Group B $(\mathrm{N}=25)$} & \multirow{2}{*}{$\begin{array}{l}\text { MWU } \\
\text { test }\end{array}$} & \multirow[t]{2}{*}{$\mathrm{P}$} \\
\hline & Mean & $\pm \mathrm{SD}$ & Range & Mean & $\pm \mathrm{SD}$ & Range & & \\
\hline S. Ferritin & 85.1 & 52.54 & $27-167.4$ & 1039.9 & 607.30 & $\begin{array}{l}292.5- \\
2000\end{array}$ & 6.08 & $<0.001(\mathrm{HS})$ \\
\hline $\mathrm{HbA1C}$ & 6.7 & 0.64 & $6.2-8.3$ & 6.42 & 0.77 & $4.5-7.1$ & 0.029 & $0.98(\mathrm{NS})$ \\
\hline PPG & 176.7 & 90.91 & $130-375$ & 162.1 & 27.13 & $130-200$ & 0.26 & 0.79 (NS) \\
\hline T. protein & 6.57 & 0.35 & $6.2-7.3$ & 6.53 & 0.22 & $6.1-6.9$ & 0.36 & $0.72(\mathrm{NS})$ \\
\hline Albumin & 3.37 & 0.22 & $3.1-3.7$ & 3.42 & 0.30 & $3-3.7$ & 0.60 & $0.54(\mathrm{NS})$ \\
\hline BUN & 125.2 & 57.99 & $26-212$ & 134.1 & 36.39 & 84-197 & 0.31 & $0.76(\mathrm{NS})$ \\
\hline Creatinine & 6.1 & 3.0 & $1.8-9.7$ & 7.11 & 2.17 & $3.5-11.4$ & 1.29 & $0.19(\mathrm{NS})$ \\
\hline $\mathrm{Hb} \%$ & 8.8 & 1.39 & $6.6-10.5$ & 9.2 & 1.32 & $6.6-10.5$ & 1.34 & $0.18(\mathrm{NS})$ \\
\hline
\end{tabular}


In studied groups

In group A mean serum ferritin before treatment was $85.1 \mathrm{ng} / \mathrm{dl}$ compared with group B mean serum ferritin before treatment was $1039.9 \mathrm{ng} / \mathrm{dl}$ wich statistically highly significant $(\mathrm{p}<.001)$

HA1C,PPG,T protein, albumin, BUN, creatinine, $\mathrm{Hb} \%$ before treatment in group A compared with group B were non significant

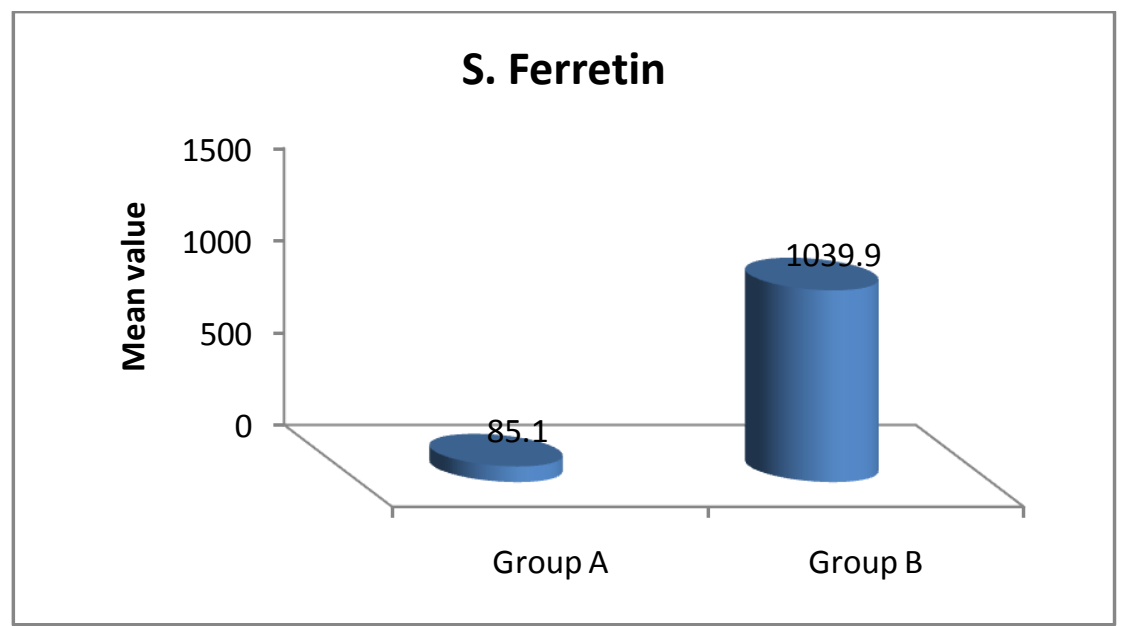

Fig. 3:- S ferritin among studied groups before treatment.

Table 6:-Comparison of serum ferritin before and after treatment among the studied groups.

\begin{tabular}{|c|c|c|c|c|c|c|c|c|c|c|}
\hline \multirow[t]{2}{*}{ Serum ferretin } & \multicolumn{4}{|c|}{ Group A $(N=25)$} & \multicolumn{4}{|c|}{ Group B $(N=25)$} & \multirow{2}{*}{$\begin{array}{l}\text { MWU } \\
\text { test }\end{array}$} & \multirow[t]{2}{*}{$\mathrm{P}$} \\
\hline & Mean & $\pm \mathrm{SD}$ & Min. & Max. & Mean & $\pm \mathrm{SD}$ & Min. & Max. & & \\
\hline $\begin{array}{l}\text { Before } \\
\text { intervention }\end{array}$ & 85.18 & 52.54 & 27.00 & 167.40 & 1039.9 & 607.30 & 292.50 & 2000.0 & 6.08 & $\begin{array}{l}<0.001 \\
\text { (HS) }\end{array}$ \\
\hline 1 month later & 515.77 & 210.68 & 320.00 & 921.00 & 885.0 & 528.48 & 250.00 & 1650.0 & 2.38 & $\begin{array}{l}0.017 \\
(\mathrm{~S})\end{array}$ \\
\hline 4 months later & 360.73 & 116.28 & 229.50 & 550.00 & 950.3 & 570.58 & 245.00 & 1650.0 & 4.75 & $\begin{array}{l}<0.001 \\
(\mathrm{HS})\end{array}$ \\
\hline Friedman test & \multicolumn{4}{|l|}{39.1} & \multicolumn{4}{|l|}{31.0} & & \\
\hline $\mathrm{P}$ & \multicolumn{4}{|c|}{$<0.001(\mathrm{HS})$} & \multicolumn{4}{|c|}{$<0.001(\mathrm{HS})$} & & \\
\hline Sig pairs & \multicolumn{4}{|c|}{$\begin{array}{l}\text { Before } \neq 1 \mathrm{~m} \\
\text { Before } \neq 4 \mathrm{~m}\end{array}$} & \multicolumn{4}{|c|}{$\begin{array}{l}\text { Before } \neq 1 \mathrm{~m} \\
\text { Befor } \neq 4 \mathrm{~m}\end{array}$} & & \\
\hline
\end{tabular}

Among studied groups

In group A mean serum ferritin before treatment $85.18 \mu \mathrm{g} / \mathrm{l}$ compared with one month later $515.77 \mu \mathrm{g} / \mathrm{l}$ and four months later $360.73 \mu \mathrm{g} / \mathrm{lwich}$ was highly significant $(\mathrm{p}<0.001)$

In group B mean serum ferritin before treatment $1039.9 \mu \mathrm{g} / \mathrm{l}$ compared with one month later $885 \mu \mathrm{g} / \mathrm{l}$ and four months later $950.3 \mu \mathrm{g} / \mathrm{lwich}$ was highly significant( $\mathrm{p}<0.001)$ In group B mean values of serum ferretin were significant high compared with group A in whole duration of study $(\mathrm{p}<0.001)$

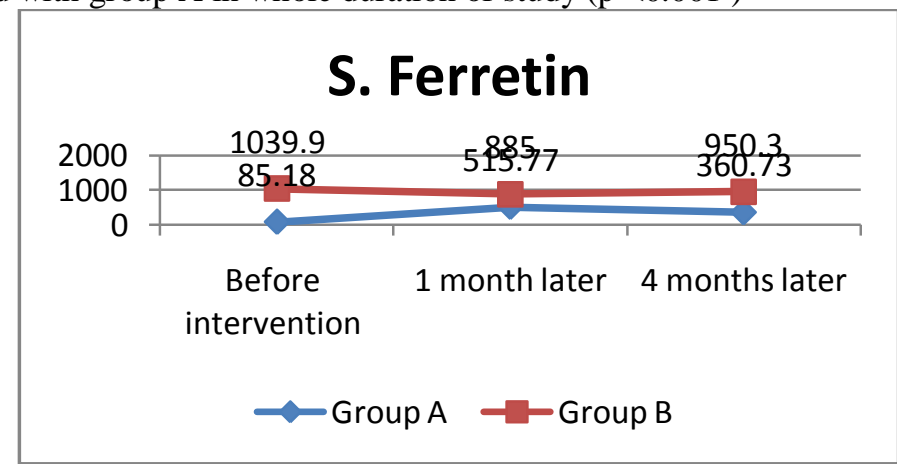

Fig 4:- S.Ferritin among groups during treatment. 
Table 7:- Comparison of hemoglobin before and after treatment among the studied groups. Among studied groups

\begin{tabular}{|c|c|c|c|c|c|c|c|c|c|c|}
\hline \multirow[t]{2}{*}{$\mathrm{Hb} \%$} & \multicolumn{4}{|c|}{ Group A $(\mathrm{N}=25)$} & \multicolumn{4}{|c|}{ Group B $(\mathrm{N}=25)$} & \multirow{2}{*}{$\begin{array}{l}\text { MWU } \\
\text { test }\end{array}$} & \multirow[t]{2}{*}{$P$} \\
\hline & Mean & $\pm \mathrm{SD}$ & Min. & Max. & Mean & $\pm \mathrm{SD}$ & Min. & Max. & & \\
\hline $\begin{array}{l}\text { Before } \\
\text { intervention }\end{array}$ & 8.80 & 1.39 & 6.6 & 10.5 & 9.26 & 1.32 & 6.6 & 10.5 & 1.34 & $0.18(\mathrm{NS})$ \\
\hline 1 month later & 10.05 & 1.03 & 8.6 & 11.0 & 10.32 & 0.75 & 9.0 & 11.2 & 1.21 & $0.22(\mathrm{NS})$ \\
\hline 4 months later & 11.06 & 0.75 & 10.5 & 12.7 & 11.01 & 0.51 & 10.3 & 12.0 & \multirow[t]{4}{*}{0.43} & 0.67 (NS) \\
\hline Friedman test & \multicolumn{4}{|c|}{46.8} & \multicolumn{4}{|l|}{48.6} & & \\
\hline $\mathrm{P}$ & \multicolumn{4}{|c|}{$<0.001$ (HS) } & \multicolumn{4}{|c|}{$<0.001$ (HS) } & & \\
\hline Sig pairs & \multicolumn{4}{|c|}{$\begin{array}{l}\text { Before } \neq 1 \mathrm{~m} \\
\text { Before } \neq 4 \mathrm{~m} \\
1 \mathrm{~m} \neq 4 \mathrm{~m}\end{array}$} & \multicolumn{4}{|c|}{$\begin{array}{l}\text { Before } \neq 1 \mathrm{~m} \\
\text { Befor } \neq 4 \mathrm{~m} \\
1 \mathrm{~m} \neq 4 \mathrm{~m}\end{array}$} & & \\
\hline
\end{tabular}

In group A mean value of $\mathrm{Hb} \%$ before treatment $8.8 \%$ compared with one month later $10.05 \%$ and four months later $11.06 \%$ which was highly significant $(\mathrm{p}<0.001)$

In group B mean value of $\mathrm{Hb} \%$ before treatment $9.26 \%$ compared with one month later $10.32 \%$ and four months later 11.01 which was highly significant $(\mathrm{p}<0.001)$

In group B mean value of $\mathrm{Hb} \%$ before treatment and one month later and four months later compared with that of group A was non significant

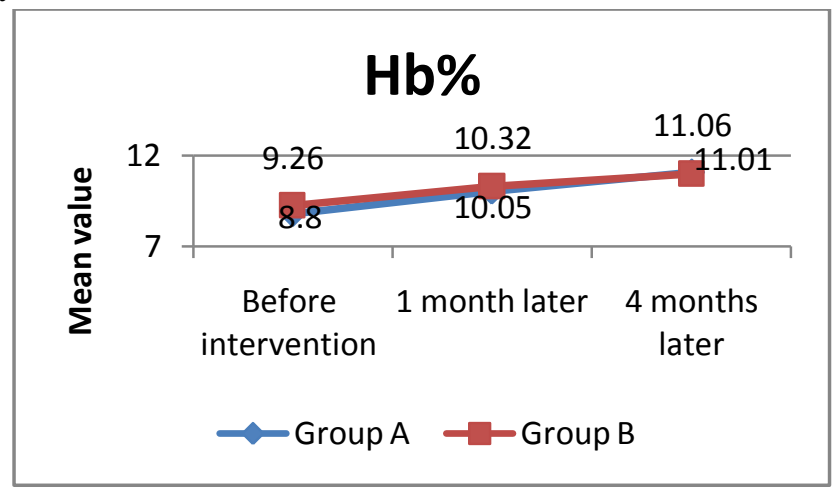

Fig. 5:- $\mathrm{Hb} \%$ value among groups during treatment

Table 8:- Comparison of fasting blood glucose before and after treatment among the studied groups.

\begin{tabular}{|c|c|c|c|c|c|c|c|c|c|c|}
\hline \multirow{2}{*}{$\begin{array}{l}\text { Fasting blood } \\
\text { glucose }\end{array}$} & \multicolumn{4}{|c|}{ Group A $(N=25)$} & \multicolumn{4}{|c|}{ Group B $(\mathrm{N}=25)$} & \multirow{2}{*}{$\begin{array}{l}\text { MWU } \\
\text { test }\end{array}$} & \multirow[t]{2}{*}{$P$} \\
\hline & Mean & $\pm \mathrm{SD}$ & Min. & Max. & Mean & $\pm \mathrm{SD}$ & Min. & Max. & & \\
\hline $\begin{array}{l}\text { Before } \\
\text { intervention }\end{array}$ & 101.6 & 27.5 & 80.0 & 150.0 & 90.8 & 13.00 & 73.0 & 110.0 & 0.519 & $0.6(\mathrm{NS})$ \\
\hline 1 month later & 102.0 & 27.1 & 81.0 & 149.0 & 95.8 & 31.79 & 74.0 & 176.0 & 1.8 & $\begin{array}{l}0.07 \\
\text { (NS) }\end{array}$ \\
\hline 4 months later & 101.6 & 27.6 & 80.0 & 151.0 & 90.2 & 12.85 & 74.0 & 111.0 & 0.517 & $\begin{array}{l}0.61 \\
(\mathrm{NS})\end{array}$ \\
\hline Friedman test & \multicolumn{4}{|l|}{3.8} & \multicolumn{4}{|l|}{5.34} & & \\
\hline $\mathrm{P}$ & \multicolumn{4}{|c|}{$0.16(\mathrm{NS})$} & \multicolumn{4}{|c|}{$0.069(\mathrm{NS})$} & & \\
\hline Sig pairs & \multicolumn{4}{|c|}{ - ----- } & \multicolumn{4}{|c|}{------- } & & \\
\hline
\end{tabular}




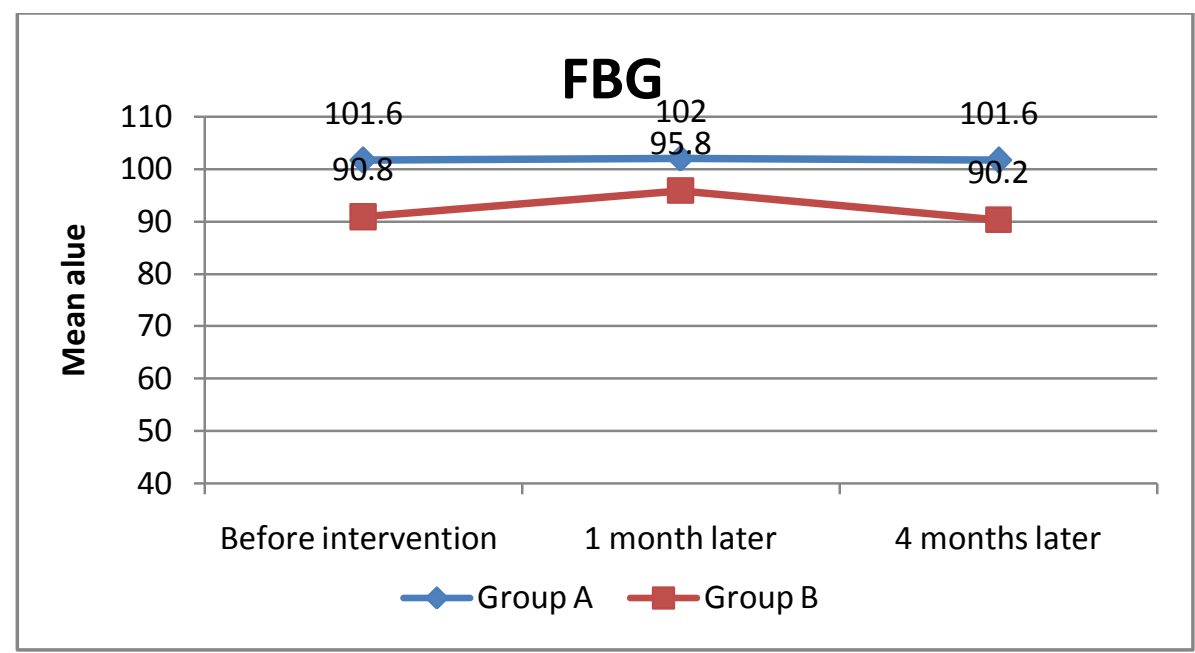

Fig 6:- FBG among the studied groups during course of treatment

Table 9:- Comparison of PP blood glucose before and after treatment among the studied groups.

\begin{tabular}{|c|c|c|c|c|c|c|c|c|c|c|}
\hline \multirow{2}{*}{$\begin{array}{l}\text { PP blood } \\
\text { glucose }\end{array}$} & \multicolumn{4}{|c|}{ Group A $(\mathrm{N}=25)$} & \multicolumn{4}{|c|}{ Group B $(\mathrm{N}=25)$} & \multirow{2}{*}{$\begin{array}{l}\text { MWU } \\
\text { test }\end{array}$} & \multirow[t]{2}{*}{$\mathrm{P}$} \\
\hline & Mean & $\pm \mathrm{SD}$ & Min. & Max. & Mean & $\pm \mathrm{SD}$ & Min. & Max. & & \\
\hline $\begin{array}{l}\text { Before } \\
\text { intervention }\end{array}$ & 176.7 & 90.91 & 130.0 & 375.0 & 151.7 & 22.59 & 130.0 & 200.0 & 1.02 & $\begin{array}{l}0.31 \\
(\mathrm{NS})\end{array}$ \\
\hline 1 month later & 178.4 & 81.4 & 120.0 & 340.0 & 146.40 & 17.41 & 125.0 & 170.0 & 0.55 & $\begin{array}{l}0.58 \\
(\mathrm{NS})\end{array}$ \\
\hline 4 months later & 174.1 & 81.98 & 125.0 & 365.0 & 140.31 & 12.76 & 120.0 & 160.0 & 0.61 & $\begin{array}{l}0.54 \\
(\mathrm{NS})\end{array}$ \\
\hline Friedman test & \multicolumn{4}{|c|}{5.10} & \multicolumn{4}{|c|}{5.37} & & \\
\hline $\mathrm{P}$ & \multicolumn{4}{|c|}{$0.1(\mathrm{NS})$} & \multicolumn{4}{|c|}{0.07 (NS) } & & \\
\hline Sig pairs & \multicolumn{4}{|c|}{-------- } & \multicolumn{4}{|c|}{------- } & & \\
\hline
\end{tabular}

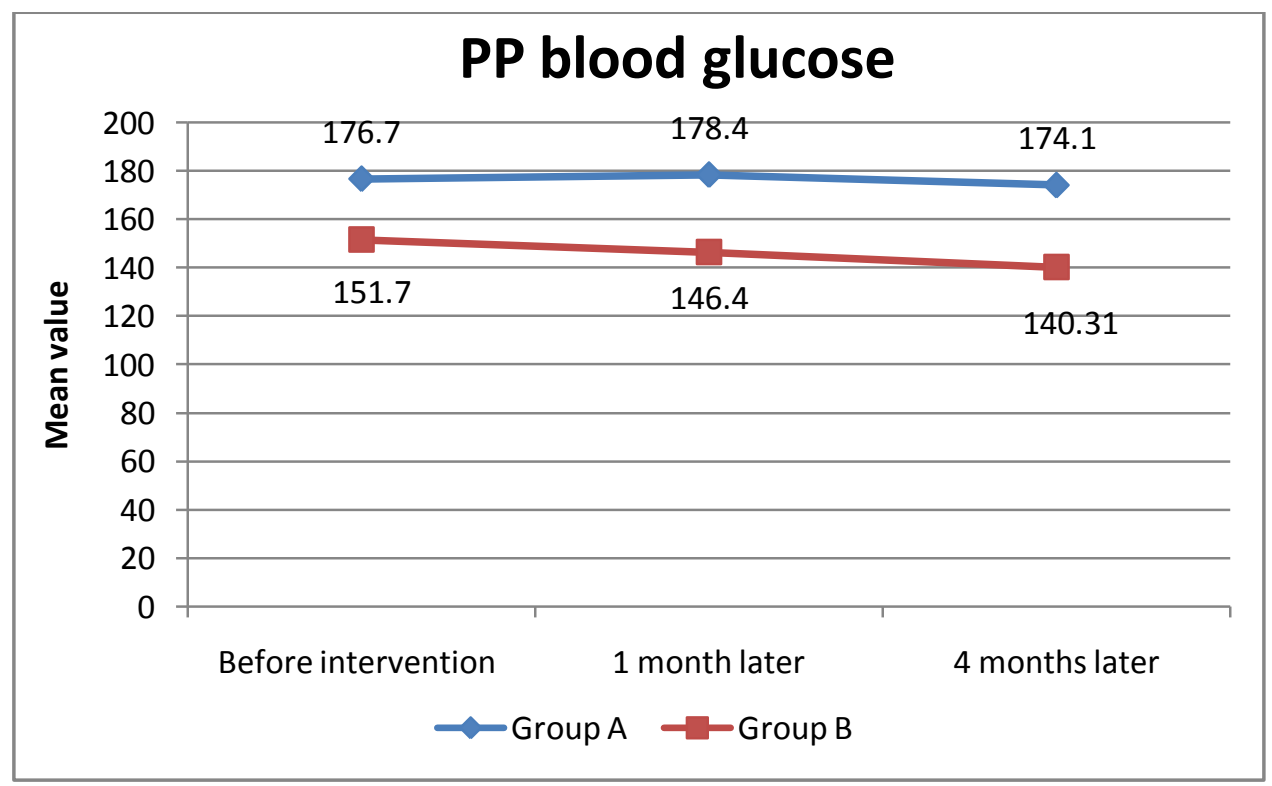

Fig 7:- PP blood glucose among studied groups 
Table 10:- Comparison of $\mathrm{HbA} 1 \mathrm{C}$ before and after intervention among the studied groups.

\begin{tabular}{|c|c|c|c|c|c|c|c|c|c|c|}
\hline \multirow[t]{2}{*}{ HbA1C } & \multicolumn{4}{|c|}{ Group A $(\mathrm{N}=25)$} & \multicolumn{4}{|c|}{ Group B $(\mathrm{N}=25)$} & \multirow{2}{*}{$\begin{array}{l}\text { MWU } \\
\text { test }\end{array}$} & \multirow[t]{2}{*}{$\mathrm{P}$} \\
\hline & Mean & $\pm \mathrm{SD}$ & Min. & Max. & Mean & $\pm \mathrm{SD}$ & Min. & Max. & & \\
\hline $\begin{array}{l}\text { Before } \\
\text { intervention }\end{array}$ & 6.70 & 0.64 & 6.20 & 8.30 & 6.42 & 0.77 & 4.50 & 7.10 & 0.029 & $\begin{array}{l}0.98 \\
\text { (NS) }\end{array}$ \\
\hline 1 month later & 6.02 & 0.94 & 5.00 & 8.10 & 5.61 & 0.82 & 4.50 & 6.90 & 1.72 & $\begin{array}{l}0.084 \\
\text { (NS) }\end{array}$ \\
\hline $\begin{array}{l}4 \\
\text { later }\end{array}$ & 5.95 & 0.76 & 5.00 & 8.00 & 5.41 & 0.91 & 4.30 & 7.00 & 2.35 & $\begin{array}{l}0.019 \\
(\mathrm{~S})\end{array}$ \\
\hline $\begin{array}{l}\text { Friedman } \\
\text { test }\end{array}$ & \multicolumn{4}{|l|}{13.9} & \multicolumn{4}{|l|}{20.5} & & \\
\hline $\mathrm{P}$ & \multicolumn{4}{|c|}{$0.001(\mathrm{HS})$} & \multicolumn{4}{|c|}{$<0.001$ (HS) } & & \\
\hline Sig pairs & \multicolumn{4}{|c|}{$\begin{array}{l}\text { Before } \neq 1 \mathrm{~m} \\
\text { Before } \neq=4 \mathrm{~m}\end{array}$} & \multicolumn{4}{|c|}{$\begin{array}{l}\text { Before } \neq 1 \mathrm{~m} \\
\text { Before } \neq 4 \mathrm{~m}\end{array}$} & & \\
\hline
\end{tabular}

Among studied groups

In group A mean value of $\mathrm{HbA1C}$ before treatment6.7\% compared with one month later $6.02 \%$ and four months later 5.95\% which was highly significant $(\mathrm{p}=0.001)$. In group B mean value of HbA1C before treatment $6.42 \%$ compared with one month later $5.61 \%$ and four months later $5.41 \%$ which was highly significant $(\mathrm{p}<0.001)$. In group B mean value of $\mathrm{HbA} 1 \mathrm{C}$ before treatment and one month later compared with that of group A was non significant but four months later was significant $(\mathrm{p}=0.019)$

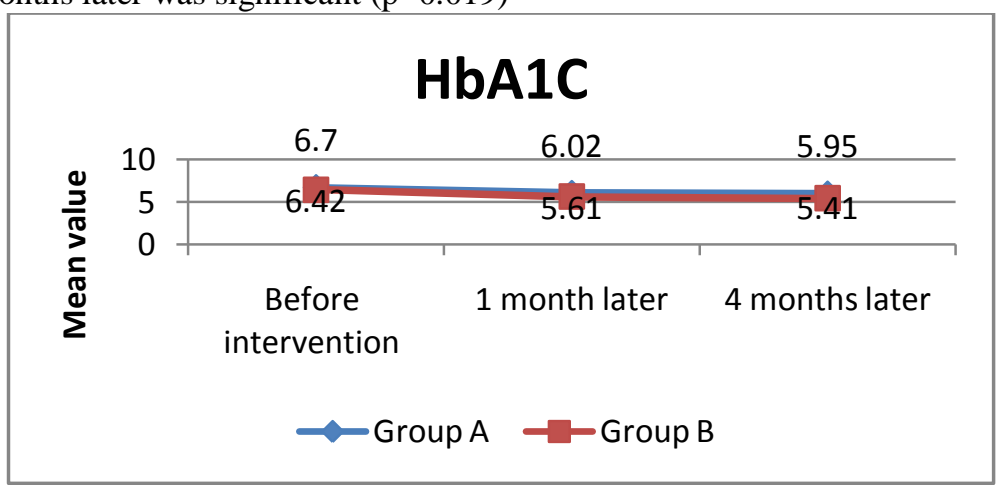

Fig 8:- HA1C among groups during treatment.

Table 11:- Correlation between HbA1c and FBG, PP blood glucose.

\begin{tabular}{|c|c|c|c|c|}
\hline \multirow[t]{3}{*}{ With } & \multicolumn{4}{|c|}{ HbA1c (before intervention) } \\
\hline & \multicolumn{2}{|c|}{ Group A } & \multicolumn{2}{|c|}{ Group B } \\
\hline & rho & $\mathrm{P}$ & rho & $\mathrm{P}$ \\
\hline FBG & 0.242 & $0.24(\mathrm{NS})$ & 0.14 & $0.49(\mathrm{NS})$ \\
\hline \multirow[t]{2}{*}{ PP bl glucose } & 0.311 & $0.0 .15(\mathrm{NS})$ & 0.329 & $0.11(\mathrm{NS})$ \\
\hline & \multicolumn{4}{|c|}{ HbA1c (1 $\mathrm{m}$ after intervention) } \\
\hline FBG & 0.016 & $0.93(\mathrm{NS})$ & 0.11 & $0.61(\mathrm{NS})$ \\
\hline \multirow[t]{2}{*}{ PP bl glucose } & 0.42 & $0.84(\mathrm{NS})$ & 0.31 & $0.16(\mathrm{NS})$ \\
\hline & \multicolumn{4}{|c|}{ HbA1c (4 m after intervention) } \\
\hline FBG & 0.07 & $0.74(\mathrm{NS})$ & 0.13 & $0.52(\mathrm{NS})$ \\
\hline PP bl glucose & 0.29 & $0.16(\mathrm{NS})$ & 0.21 & $0.32(\mathrm{NS})$ \\
\hline
\end{tabular}

This table showed non significant Correlation between HbA1c and FBG, PP blood glucose.

Table 12:- Comparison of total protein before and after intervention among the studied groups..

\begin{tabular}{|l|l|l|l|l|l|l|l|l|l|l|}
\hline Total protein & \multicolumn{4}{|l|}{ Group A (N=25) } & \multicolumn{3}{l|}{ Group B (N=25) } & MWU & P \\
& Mean & \pm SD & Min. & Max. & Mean & \pm SD & Min. & Max. & test \\
\hline $\begin{array}{l}\text { Before } \\
\text { intervention }\end{array}$ & 6.57 & 0.35 & 6.20 & 7.30 & 6.53 & 0.23 & 6.10 & 6.90 & 0.36 & $\begin{array}{l}0.71 \\
(\mathrm{NS})\end{array}$ \\
\hline 1 month later & 6.71 & 0.45 & 6.00 & 7.40 & 6.58 & 0.22 & 6.30 & 7.00 & 1.04 & $\begin{array}{l}0.29 \\
(\mathrm{NS})\end{array}$ \\
\hline
\end{tabular}




\begin{tabular}{|c|c|c|c|c|c|c|c|c|c|c|}
\hline 4 months later & 6.83 & 0.42 & 6.50 & 7.50 & 6.70 & 0.26 & 6.30 & 7.30 & 0.02 & $\begin{array}{l}0.98 \\
\text { (NS) }\end{array}$ \\
\hline Friedman test & \multicolumn{4}{|c|}{3.1} & \multicolumn{4}{|c|}{5.1} & & \\
\hline $\mathrm{P}$ & \multicolumn{4}{|c|}{$0.21(\mathrm{NS})$} & \multicolumn{4}{|c|}{0.1 (NS) } & & \\
\hline Sig pairs & \multicolumn{4}{|c|}{-------- } & \multicolumn{4}{|c|}{------ } & & \\
\hline
\end{tabular}

Among studied groups,mean values of T. Protein in group A and group B along course of treatment were non significant.

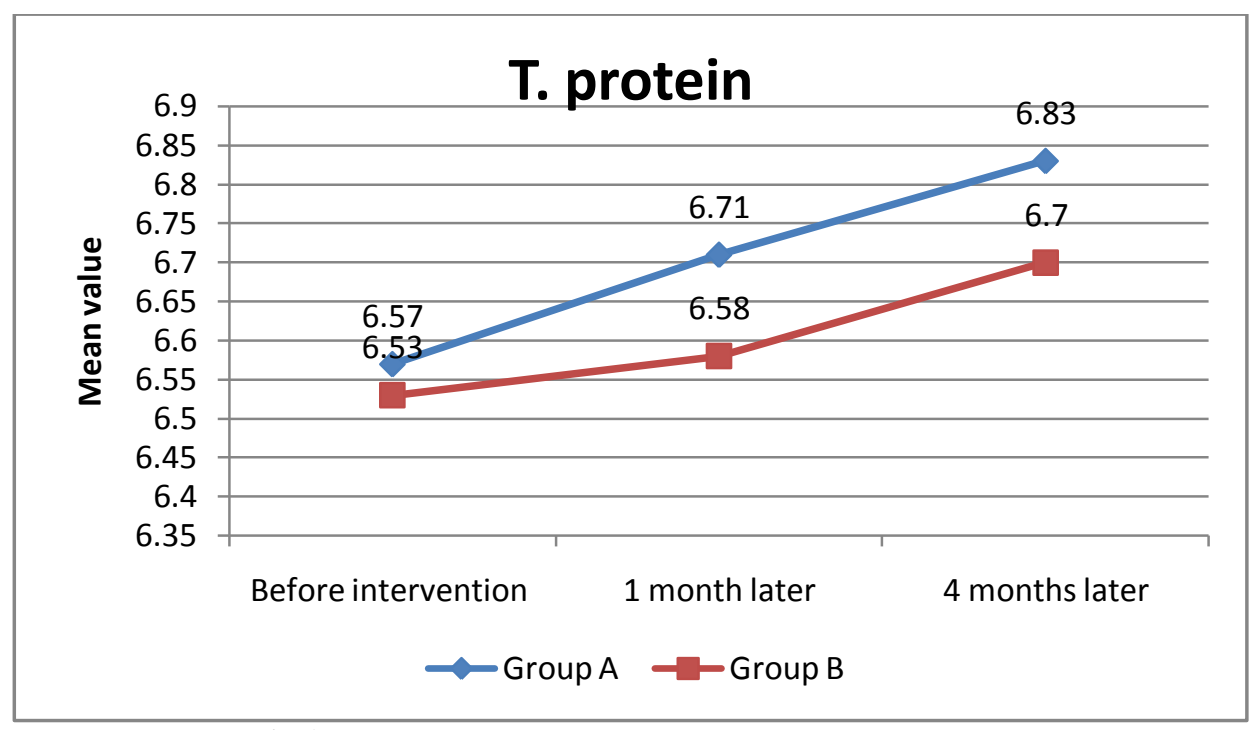

Fig 9:- T.Protein value among groups during treatment

Table 13:- Comparison of albumin before and after treatment among the studied groups.

\begin{tabular}{|c|c|c|c|c|c|c|c|c|c|c|}
\hline \multirow{2}{*}{ Albumin } & \multicolumn{4}{|c|}{ Group A $(N=25)$} & \multicolumn{4}{|c|}{ Group B $(\mathrm{N}=25)$} & \multirow{2}{*}{$\begin{array}{l}\text { MWU } \\
\text { test }\end{array}$} & \multirow[t]{2}{*}{$\mathrm{P}$} \\
\hline & Mean & $\pm \mathrm{SD}$ & Min. & Max. & Mean & $\pm \mathrm{SD}$ & Min. & Max. & & \\
\hline $\begin{array}{l}\text { Before } \\
\text { intervention }\end{array}$ & 3.37 & 0.22 & 3.10 & 3.7 & 3.42 & 0.30 & 3.0 & 3.7 & 0.60 & $\begin{array}{l}0.54 \\
\text { (NS) }\end{array}$ \\
\hline 1 month later & 3.53 & 0.19 & 3.20 & 3.8 & 3.46 & 0.28 & 3.1 & 3.9 & 1.09 & $\begin{array}{l}0.27 \\
\text { (NS) }\end{array}$ \\
\hline 4 months later & 3.66 & 0.22 & 3.40 & 4.0 & 3.53 & 0.18 & 3.2 & 3.8 & 1.61 & $\begin{array}{l}0.11 \\
\text { (NS) }\end{array}$ \\
\hline Friedman test & \multicolumn{4}{|l|}{5.04} & \multicolumn{4}{|c|}{4.97} & & \\
\hline $\mathrm{P}$ & \multicolumn{4}{|c|}{0.061 (NS) } & \multicolumn{4}{|c|}{0.08 (NS) } & & \\
\hline Sig pairs & \multicolumn{4}{|c|}{------- } & \multicolumn{4}{|c|}{-------- } & & \\
\hline
\end{tabular}

Among studied groups

Mean values of albumin in group A and group B along course of treatment were non significant. 


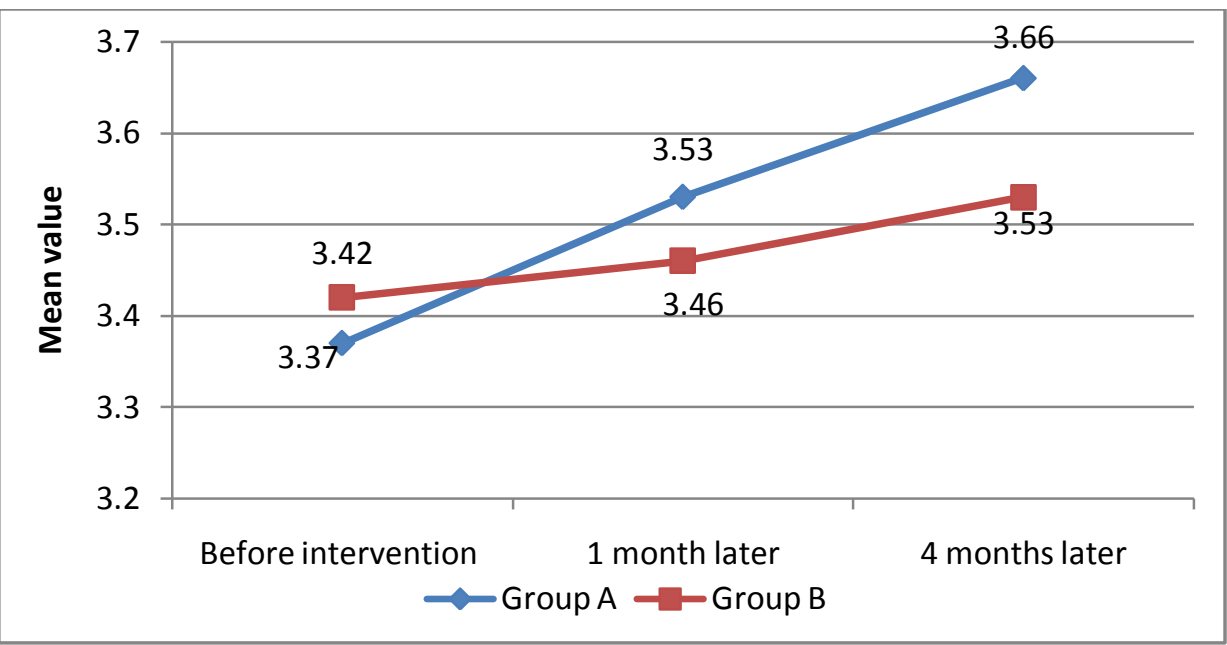

Fig.10:- Albumin value among groups during treatment

Table 14:- Comparison of Creatinine before and after treatment among the studied groups.

\begin{tabular}{|c|c|c|c|c|c|c|c|c|c|c|}
\hline \multirow[t]{2}{*}{ Creatinine } & \multicolumn{4}{|c|}{ Group A $(\mathrm{N}=25)$} & \multicolumn{4}{|c|}{ Group B $(\mathrm{N}=25)$} & \multirow{2}{*}{$\begin{array}{l}\text { MWU } \\
\text { test }\end{array}$} & \multirow[t]{2}{*}{$\mathrm{P}$} \\
\hline & Mean & $\pm \mathrm{SD}$ & Min. & Max. & Mean & $\pm \mathrm{SD}$ & Min. & Max. & & \\
\hline $\begin{array}{l}\text { Before } \\
\text { intervention }\end{array}$ & 6.14 & 3.07 & 1.80 & 9.70 & 7.11 & 2.17 & 3.50 & 11.40 & 1.29 & $\begin{array}{l}0.19 \\
(\mathrm{NS})\end{array}$ \\
\hline 1 month later & 5.91 & 2.88 & 1.80 & 9.50 & 6.31 & 1.85 & 3.50 & 9.50 & 0.84 & $\begin{array}{l}0.41 \\
(\mathrm{NS}) \\
\end{array}$ \\
\hline 4 months later & 7.59 & 3.74 & 2.50 & 14.10 & 6.79 & 2.27 & 3.60 & 10.50 & 0.44 & $\begin{array}{l}0.66 \\
(\mathrm{NS})\end{array}$ \\
\hline Friedman test & \multicolumn{4}{|l|}{3.2} & \multicolumn{4}{|l|}{4.93} & & \\
\hline $\mathrm{P}$ & \multicolumn{4}{|c|}{$0.19(\mathrm{NS})$} & \multicolumn{4}{|c|}{0.09 (NS) } & & \\
\hline Sig pairs & \multicolumn{4}{|c|}{--------- } & \multicolumn{4}{|c|}{---------- } & & \\
\hline
\end{tabular}

Mean values of creatinine in group A and group B along course of treatment were non significant.

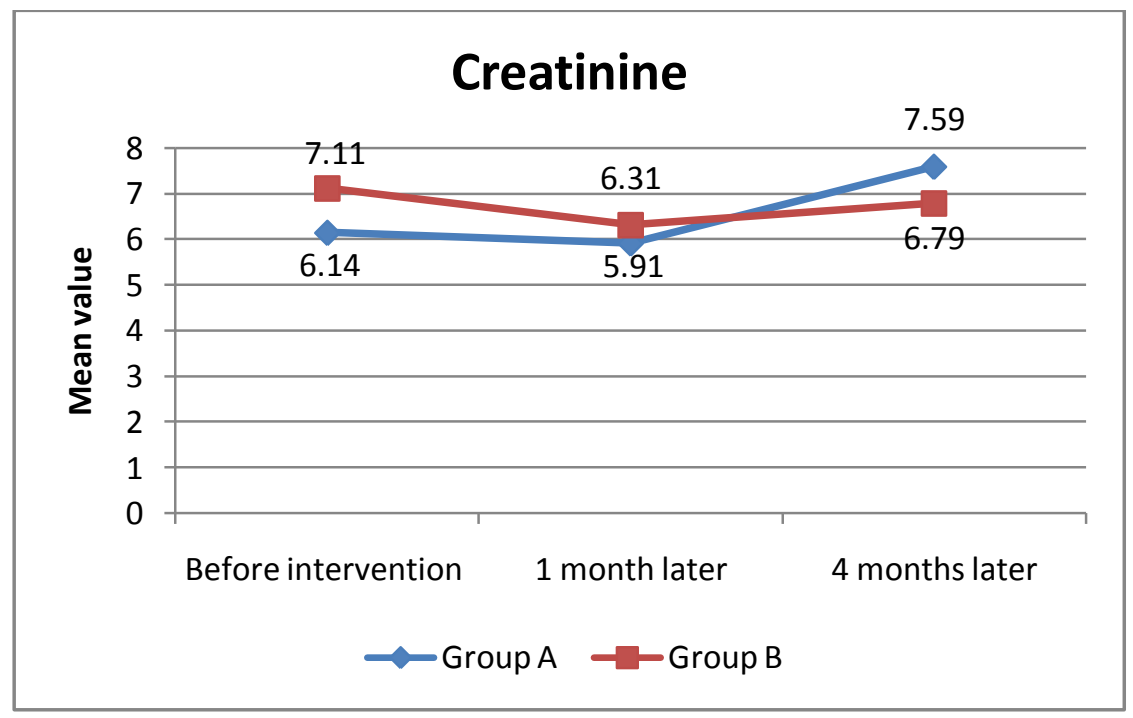

Fig 11:- Creatinine value among groups during treatment 
Table 15:- Comparison of Blood urea nitrogen before and after treatment among the studied groups.

\begin{tabular}{|c|c|c|c|c|c|c|c|c|c|c|}
\hline \multirow[t]{2}{*}{ BUN } & \multicolumn{4}{|c|}{ Group A $(\mathrm{N}=25)$} & \multicolumn{4}{|c|}{ Group $\mathrm{B}(\mathrm{N}=25)$} & \multirow{2}{*}{$\begin{array}{l}\text { MWU } \\
\text { test }\end{array}$} & \multirow[t]{2}{*}{$\mathrm{P}$} \\
\hline & Mean & $\pm \mathrm{SD}$ & Min. & Max. & Mean & $\pm \mathrm{SD}$ & Min. & Max. & & \\
\hline $\begin{array}{l}\text { Before } \\
\text { intervention }\end{array}$ & 122.41 & 43.39 & 26.0 & 212.0 & 123.21 & 37.85 & 84.0 & 197.0 & 0.92 & $\begin{array}{l}0.34 \\
\text { (NS) }\end{array}$ \\
\hline 1 month later & 119.44 & 53.48 & 40.0 & 210.0 & 117.82 & 35.92 & 80.0 & 195.0 & 0.87 & $\begin{array}{l}0.38 \\
(\mathrm{NS})\end{array}$ \\
\hline 4 months later & 113.92 & 48.30 & 50.0 & 200.0 & 115.00 & 34.03 & 85.0 & 190.0 & 0.44 & $\begin{array}{l}0.66 \\
(\mathrm{NS})\end{array}$ \\
\hline Friedman test & \multicolumn{4}{|c|}{4.63} & \multicolumn{4}{|c|}{3.84} & & \\
\hline $\mathrm{P}$ & \multicolumn{4}{|c|}{$0.092(\mathrm{NS})$} & \multicolumn{4}{|c|}{$0.15(\mathrm{NS})$} & & \\
\hline Sig pairs & \multicolumn{4}{|c|}{-------- } & \multicolumn{4}{|c|}{-------- } & & \\
\hline
\end{tabular}

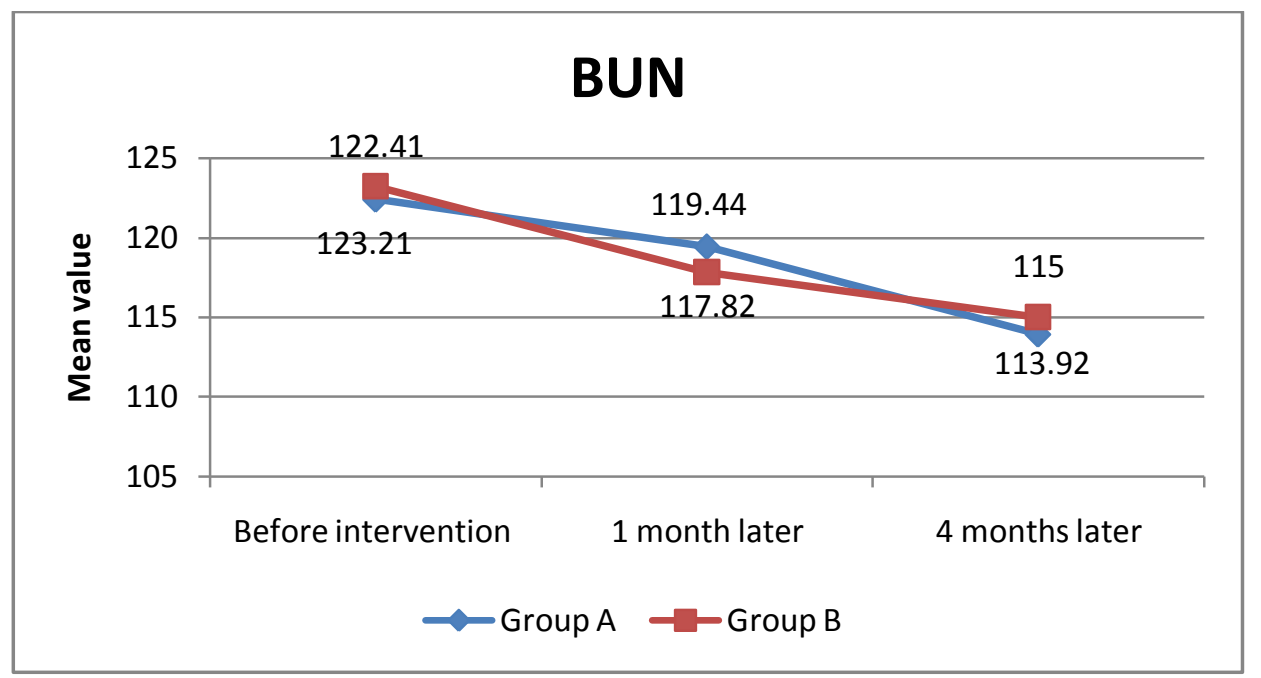

Fig 12:- BUN value among groups during treatment.

\section{Discussion:-}

A1c is the most widely accepted and used method of assessing chronic glycemia in patients with diabetes. It is formed by the irreversible binding of glucose to hemoglobin over the lifespan of the erythrocytes (Goldstien et al., 2004).

Patients with Chronic kidney disease (CKD) are commonly anemic due to a variety of reasons, including functional or absolute iron deficiency and erythropoietin insufficiency (Gotloib et al., 2006). Treatment of anemia in patients with CKD using iron replacement therapy and erythropoietin-stimulating agents (ESAs) has resulted in significant improvements to quality of life and the correction of anemia without the need for blood transfusions (NCCCCA, et al., 2006, and Nissenson et al., 1999).

ESAs and intra venous iron are commonly used therapies in the management of anemia in patients with CKD. Patients with both diabetes and CKD have a higher prevalence of severe anemia compared with patients with CKD alone (Thomas et al.,2003).

For the purpose of detecting new cases of diabetes, in those with an initial $\mathrm{A} 1 \mathrm{C}<6.0 \%$, rescreening at intervals shorter than 3 years identifies few individuals $(\sim \leq 1 \%)$ with an $\mathrm{A} 1 \mathrm{C} \geq 6.5 \%$. At $\mathrm{A} 1 \mathrm{C} \geq 6 \%$, rescreening even at a 1 year interval would be reasonable strategy to identify disease. ( Osamu et al., 2016)

One of categories of increased risk for type2 diabetes (Prediabetes )(ADA 2016 Guidelines)was A1C equal 5.7$6.4 \%(39-46 \mathrm{mmol} / \mathrm{mol})$ 


\section{The aim of this thesis was to evaluate:-}

The effect of iron and erythropoietin treatment on the $\mathrm{HbA} 1 \mathrm{c}$ of hemodialysis patient with diabetes.

This study was conducted on $50 \mathrm{HD}$ patients with type-2 diabetes. All patients was chosen from those attending Banha University Hospitals. The diagnosis of diabetes was based on a history of diabetes or on the ADA criteria. Information collected from participants included demographic data, height, weight (dry weight in HD patients), duration of diabetes and duration of HD. Patients with diabetes was restricted to those with stable blood glucose and whose diabetes treatment had not been altered during the preceding 6 months before the determination of HbA1c.

The patients was classified into two groups (each consists of 25 patients).

The first group (group A): It included patients selected for iron therapy with serum ferritin values $<200 \mu \mathrm{g} / \mathrm{l}$. All patients had hemoglobin $\leq 10.5 \mathrm{~g} / \mathrm{dl}$. Patients in this group were not on previous or concurrent ESA therapy and were vitamin B12 and folate replete. Intravenous iron was given as a single dose in the form of low-molecular weight iron dextran dependent on the patient's body weight. This was delivered as an initial intravenous test infusion of $100 \mathrm{mg}$ of iron over $1 \mathrm{~h}$ followed by the remaining dose over the next $2-4 \mathrm{~h}$.

The second group (group B):It consisted of patients who needed ESA treatment with serum ferritin value $>200 \mu \mathrm{g} / \mathrm{l}$. All patients receiving ESA therapy had hemoglobin $<$ or $=10.5 \mathrm{~g} / \mathrm{dl}$ and were considered iron, vitamin B12, and folate replete prior to initiation. Patients were considered iron replete following a serum ferritin value $>200 \mu \mathrm{g} / \mathrm{l}$ or having received intravenous iron at least 6 weeks prior to ESA therapy.The dose of ESA was titrated monthly to achieve target hemoglobin $10.5-12 \mathrm{~g} / \mathrm{dl}$.

All patients were subjected to complete history taking( age, sex, type of diabetes ,medications and duration of HD ) , complete physical examination investigated for HA1C, rondom blood glucose, S.Ferretin, T.Protein, albumin,BUN, creatinine before treatment, one month later and four month later.

The result of this work were tabulated and statistically analysed using suitable statistical tests.

The results of this study were that, in group A patients, parentral iron administration was attended with a significant rise of serum ferretin after four months.in group B, serum ferretin showed a significant fall four months after ESA therapy.Table(6)Fig(4).

In this study, there was significant improvement in haemoglobin level in both groups( in group A mean hemoglobin after four months $11.06 \%$ compared with before therapy $8.85 \%(\mathrm{p}<0.001)$, in group B mean hemoglobin after four months $11.01 \%$ compared with before therapy $9.26 \%(\mathrm{p}<0.001))$ with treatment and a decrease in the number of patients requiring blood transfusions. Table(7)Fig(5).

The other results came in coordination with,(Thomas et al.,2003) who reported that anemia of CKD was improved by ESAs and intra venous iron, (Muñoz et al.,2008) who reported that administration of ESAs and iron managed the anemia of CKD and achieved target haemoglobin level, and (Lucia et al.,2016)who reported that anemia in CKD was managed primary with ESAs and iron therapy.

In our study, the dose of ESA was titrated monthly to achieve target hemoglobin of $10.5-12 \mathrm{gm} / \mathrm{dl}$ and this resulted in correction of anemia and improvement of quality of life. In agreement with our study, several studies have demonstrated that the correction of anemia in patients with chronic kidney disease improves the quality of life and exercise tolerance while reducing the need for transfusion.(Al-Khoury et al., 2007),( Teehan.,1991)

The $2006 \mathrm{NKF}$ KDOQI-recommended target $\mathrm{Hb}$ concentration is $>11-12 \mathrm{~g} / \mathrm{dl}$, with recommendations against routinely maintaining $\mathrm{Hb}$ concentrations of $>13 \mathrm{~g} / \mathrm{dl}$ in patients with CKD (National Kidney Foundation, 2006).

On the other hand, the CHOIR trial studied the outcomes of anemia treatment in over 1400 CKD patients who had a hemoglobin $<11 \mathrm{~g} / \mathrm{dl}$ at entry. Enrolled subjects were randomly assigned to EPO therapy treatment protocols designed to achieve a target hemoglobin levels of either $13.5(\mathrm{n}=715)$ or $11.3 \mathrm{~g} / \mathrm{dl}(\mathrm{n}=717)$. The study was terminated prematurely due to higher mortality rates adverse events in the group with higher targeted Hb levels (Singh et al., 2006), (Teehan and Benz.,2011).

(Pfeffer et al., 2009 )reported that despite the increased usage of ESA agents, his findings had shown that the correction of anemia to levels of hemoglobin in excess of $12.5 \mathrm{~g} / \mathrm{dl}$ in patients with type 2 diabetes using this therapy had not led to an improvement in mortality but rather an increased risk of stroke. This study showed that iron and 
ESA treatments result in a significant fall in $\mathrm{A} 1 \mathrm{C}$ in patients with diabetes and CKD, the change was independent of glycemic changes. Table (11).In group A mean value of $\mathrm{HbA1C}$ before treatment was $6.7 \%$ compared withHbA1C four months after which was $5.95 \%$. In group B the mean value of $\mathrm{HbA1C}$ before treatment was $6.42 \%$ whereas HbA1C after four months was $5.41 \%$.Table (10) Fig(8). This study showed no significant change occur in fasting and post prandial levels among groups during course of treatment. Table $(8,9)$ Fig $(6,7)$. This study showed non significant Correlation between HbA1c and FBG, PP blood glucose among groups during the course of the study. Table (11).This results came in coordination with (Sunil et al., 2010) who achieved a similar study and reported that despite a lack of change of glycemic control in the both groups, A1C concentrations fell significantly $(\mathrm{P}<0.001$ and 0.013, respectively, for groups A and B).The effect of the lowering of the A1c values following either treatment has been postulated to be secondary to the formation of new erythrocytes in the blood stream, causing a change of proportion of young to old cells, and also from an alteration in the red-cell glycation rates (Brooks et al, 1980, and Kim et al, 2006). Discordantly high A1C values compared with glucose readings have been reported in previous studies and case reports on non diabetic patients with iron deficiency and in patients with type 1 diabetes in childhood and pregnancy (Hashimoto,2008, Brooks et al, 1980, and Kim et al, 2006). Hemolytic anemia as well as recovery from acute blood loss seem to have the opposite effect to iron deficiency by reducing HbAlc in affected individuals. Reports have shown that abnormally low HbAlc levels may be associated to conditions such as hereditary spherocytosis, elliptocytosis, autoimmune or drug-induced hemolytic anemia, and anemia due to chronic renal failure. These conditions are characterized by reduced red cell survival and therefore by a reduction in the availability of hemoglobin for glycation(Jiao et al., 1998, Herranz et al.,1999, Liew andCheah , 2003, Kutter and Thoma ,2006 and Lum ,2010). High levels of urea in the blood can lead to formation of carbamylated hemoglobin that can interfere with some methods of HbA1c measurement. However, carbamylated hemoglobin does not present an analytical interference in most modern methods of measurement (Weykamp et al ., 1993). The correction of the iron deficiency in all patient groups leaded to a significant fall in A1C values in our study.

Several studies have also shown a fall in A1C concentrations following ESA treatment in patients with diabetes undergoing hemodialysis (Inaba et al, 2007 ,Nakao et al.,1998).(Nakao et al.,1998) reported a fall in A1C in non diabetic patients with CKD on hemodialysis following ESA therapy.

Good glycemic control in patients with diabetes and CKD has been shown to be associated with better survival rates (Morioka, 2001).

The results of our study showed statistically significant falls in the A1C following iron and ESA treatment (mean $5.95 \%$ following iron and $5.41 \%$ following ESA) in the absence of a change in glycemic control. It showed that $\mathrm{A} 1 \mathrm{C}$ can be unreliable and can fall following treatment with both iron and ESA therapy.

(Sunil et al., 2010). Fluctuations of A1C that can occur in this patient group(patients with diabetes and CKD who were treated with iron or ESA therapy)so alternative methods for measuring glycemic control such as capillary glucose testing and CGM should be used, and therapy should not be based on the A1C value alone.

It has been shown that $62 \%$ of the population variance in HbA1c level is genetically determined(Jeffcoate, 2004).

(Inaba et al.,2007).Glycated albumin has been suggested as an alternative marker to represent glycemic control, as it was noted to be similar (in contrast to A1C, which was higher) in patients with iron deficiency and pre-ESA compared with patients post therapy

It is known that glycation among various proteins is increased in diabetic patients compared with non-diabetic subjects. Currently, among these glycated proteins, glycated hemoglobin (HbA1C) is used as the gold standard index of glycemic control in clinical practice for diabetes treatment. However, HbA1C does not accurately reflect the actual status of glycemic control in some conditions where plasma glucose changes during short term, and in patients who have diseases such as anemia and variant hemoglobin. In comparison, another index of glycemic control, glycated albumin (GA), more accurately reflects changes in plasma glucose during short term and also postprandial plasma glucose. Although GA is not influenced by disorders of hemoglobin metabolism, it is affected by disorders of albumin metabolism. Some diseases and pathological conditions where GA measurement is useful. These include the status of glycemic control changes during short term, diseases which cause postprandial hyperglycemia, iron deficiency anemia, pregnancy, chronic liver disease (liver cirrhosis), chronic renal failure (diabetic nephropathy), and variant hemoglobin (Masafumi and Soji, 2010). 
This study managed to show that A1C values fell significantly both with iron and ESA. This change in A1C was independent of changes in glycemic control. Intravenous iron and ESA are increasingly common therapies used in the management of anemia in patients with CKD and diabetes. The present study has been able to confirm that reported changes in $\mathrm{A} 1 \mathrm{C}$ following these treatments are independent of changes in glycemic control; therefore, caution is warranted in the interpretation of $\mathrm{A} 1 \mathrm{C}$ and management of glycemia when based on $\mathrm{A} 1 \mathrm{C}$ alone.

At a time when self monitoring of blood glucose is being discouraged, especially in non-insulin treated patients Regular capillary glucose measurements, and the concurrent use of CGM if available, seems essential in order to accurately assess glycemic control in this group of patients. (Simon et al., 2008).

This study showed no significant change occur in T. Protein, albumin, BUN, and creatinine levels among groups during course of treatment.Table $(12,13,14,15)$ Fig $(9,10,11,12)$. This study showed no significant value of duration of diabetes and duration of hemodialysis.Table (3) Fig (2).

\section{Conclusion:-}

A1c is the most widely accepted and used method of assessing chronic glycemia in patients with diabetes. This is study to showed that iron and ESA treatments result in a fall in A1C, which is independent of glycemic changes in patients with diabetes and CKD.

\section{References:-}

1. Al-Khoury(2007) : Characteristics ofAnaemia Management in Patients with Chronic Kidney Disease Am J Kidney Dis, Vol.50, pp. $474-6$

2. American Diabetes Association. (2016) : guidelines of diagnosis and screening of diabetes. diabetes care.

3. Brooks Ap I Metcalfe J 1 Day JL 1 Edwards MS .Iron deficiency and glycosylated haemoglobin A. Lancet1980; $2: 141$.

4. Goldstein DE, Little RR, Lorenz RA, Malone JI, Nathan D, Peterson CM, Sacks DB. Tests of glycemia in diabetes. Diabetes Care 2004;27:1761-1773

5. Gram Hansen pIEriksenJlMourits- Andersen T 1 OlesenL.Giycosylatedhaemoglobin (HbA1c) Bin iron- and vitamin B 12 deficiency. J Intern Med 1990; 227:133-136

6. Hashimoto K, Noguchi S, Morimoto Y, Hamada S, Wasada K, Imai S, Murata Y,Kasayama S, KogaM. A1C but not serumglycated albumin is elevated in late preg-nancy owing to iron deficiency.DiabetesCare 2008;31:19451948

7. Herranz L, Grande C, Janez M. et al., (1999): Red blood cell auto-antibodies with a shortened erythrocyte life span as a cause of lack of relation between glycosylated hemoglobin and mean blood glucose levels in a woman with type 1 diabetes. Diabetes Care;22(12):2085-6.

8. Jeffcoate S (2004) : Diabetes control and complications: the role of glycatedhaemoglobin, 25 years on. Diabetic Med, 21:657-665.

9. Jiao Y, Okumiya T, Saibara T et al., (1998): Abnormally decreased HbA1c can be assessed with erythrocyte creatine in patients with a shortened erythrocyte age. Diabetes Care;21(10):1732-5.

10. kimCl Bullard KM I Herman WH I Beckles GL. Association between iron deficiency and Hbalc levels among adults 2006

11. Kutter D and Thoma J (2006):Hereditary spherocytosis and other hemolytic anomalies distort diabetic control by glycated hemoglobin. Clin Lab;52(9-10):477-81.

12. Liew CF and Cheah JS (2003): Hereditary spherocytosis, a pitfall in the assessment of glycaemic control. Singapore Med J;44(2):94-7.

13. Inaba M 1 OKuno S 1 Kumeda Y 1 Yamada S 1 lrnanishi Y1 Tabata T Okamura M 1 Okada T11shimura E1 Nlshizawa Y. Glycated albumin is a better glycemic indicator than glycated hemoglobin Values in hemodialysis patients With diabetes :effect of anemia and erythropoietin injection . Jam Soc Nephrol2007; 18 :896-903

14. Lucia Del Vecchio*, Selena Longhi and Francesco Locatelli (2016):Safety concerns about intravenous iron therapy in patients with chronic kidney disease :Clin Kidney J doi: 10.1093/ckj/sfv142Volume 94, Issue 3April 2008 Pages 172-18

15. Lum G. (2010): Artefactually low hemoglobin A1c in a patient with hemolytic anemia. Lab Med;41(5):267-70.

16. M. Muñoz, J. A. García-Erce, S. Gómez-Ramírez, J. Comin and E (2008): Efficacy and safety of intravenous iron therapy: VoxSanguinis, Pages 172183.

17. Masafumi Koga and SojiKasayama (2010): Clinical impact of glycated albumin as another glycemic control marker. Endocrinal journal ;vol.57 No.9p:751-762 
18. Morioka T, Emoto M, Tabata T, Shoji T, Tahara H, Kishimoto H, IshimuraE,Nishizawa Y. Glycemic control is a pre-dictor of survival for diabetic patients onhemodialysis. Diabetes Care 2001;24:909 -913

19. Nakao T 1 Matsumoto H1 Okada T1 Han M 1 Hidaka H1 Yoshino M 1 Shino T1Yamada C1 Nagaoka Y. Influence of erythropoietin treatment onhemoglobin Ale levels in patients with chronic renal failure on hemodialysis.Intern Med $1998 ; 37: 826-830$

20. National Collaborating Centre For Chronic Conditions Anaemiamanagement in Chronic Kidney disease(2006) : national clinical guidelineformanagement in adults and children London : Royal College Of Physicians2006.

21. Ng JMI Jennings PE I Laboi PI JayagopalV.Erythropoetin treatment significantly alters measured glycatedhaemoglobin (HbAlc).Diabet Med 2008; 25:239-240

22. Nissenson AR1Strobos J .Iron deficiency in patients with renal failure .Kidney lnt 1999;55:S18-S21

23. Osamu Takahashi, Andrew J. Farmer, FRCGPet al.,(2016): A1C to Detect Diabetes in Healthy Adults.Diabetes Care ; 33(9)

24. Pfeffer MA, Burdmann EA, Chen C-Y,Cooper ME, de Zeeuw D, EckardtKU,Feyzi JM, Ivanovich P, KewalramaniR,Levey AS, Lewis EF, McGill JB, McMurrayJJ, Parfrey P, Parving HH, RemuzziG,Singh AK, Solomon SD, Toto R. A trial ofdarbepoetinalfa in type 2 diabetes andchronic kidney disease. N Engl J Med2009;361:2019-203

25. Simon J, Gray A, Clarke P, Wade A, NeilA, Farmer A. Cost effectiveness of selfmonitoring of blood glucose in patientswith non-insulin treated type 2diabetes:economic evaluation of data from the DiGEM trial. BMJ 2008;336:1177-1180

26. Singh A, Szczech L, Tang K(2006): Correction of Anemia with Epoetin Alfa in Chronic Kidney Disease. N Engl J Med.;335:2085-98

27. SUNIL BHANDARI,STEPHEN L. ATKIN,ERIC S. KILPATRICK, et al (2010):The Effect of Iron and Erythropoietin Treatment on the A1C., Diabetes care 33(11):2310-3 - DOI: 10.2337/dc10-0917 .

28. Teehan G and BenzRL (2011): An Update on the Controversies in Anemia Management in Chronic Kidney Disease: Lessons Learned and Lost. Anemia; 201:623673.

29. Teehan, S. Krantz, W. A. Stone et al (1991) "Double-blind, placebo-controlled study of the therapeutic use of recombinant human erythropoietin for anemia associated with chronic renal failure in predialysis patients," American Journal of Kidney Diseases, vol. 18, no. 1, pp. 50-59.

30. Thomas MC, MacIsaac RJ, TsalamandrisC, Power D, Jerums G. Unrecognized anemia in patients with diabetes: a cross-sectional survey. Diabetes Care 2003;26:1164 -1169

31. Weykamp CW, Penders TJ, Siebelder CW. et al., (1993): Interference of carbamylated and acetylated hemoglobins in assays of glycohemoglobinby HPLC, electrophoresis, affinity chromatography, and enzyme immunoassay. ClinChem; 39(1):138-42. 